\title{
Vitamin D supplementation could reduce risk of sepsis in infants
}

\section{Letter to the Editor}

A recent paper in this journal identified sepsis syndrome as an important postoperative risk factor for infants below the age of six months and stated that adequate prevention and therapeutic strategies warrant further prospective investigations. ${ }^{[1]}$ Sepsis is caused by bacterial infection. The hormonal metabolite of vitamin D, 1,25-dihydroxyvitamin D, induces production of human cathelicidin, LL-37, which has antimicrobial and antiendotoxin effects that contribute to innate immune response to sepsis. ${ }^{[2]}$ Based on a review of the epidemiology of sepsis in the United States (high rates in winter, low rates in summer, high rates in the northeast, low rates in the west, ${ }^{[3]}$ higher rates for African-Americans than white Americans, and comorbid diseases linked to low serum 25-hydroxyvitmin $\mathrm{D}[25(\mathrm{OH}) \mathrm{D}])$, it was hypothesized that higher serum $25(\mathrm{OH}) \mathrm{D}$ levels could reduce the risk of sepsis. ${ }^{[4]}$ That hypothesis was quickly supported in a study of those with sepsis in an intensive care unit of a hospital in Atlanta, Georgia, finding that those in the intensive care unit with or without sepsis had much lower serum $25(\mathrm{OH}) \mathrm{D}$ levels than others in the community. ${ }^{[5]}$ Thus, it would be worthwhile supplementing infants preparing for surgery with vitamin $\mathrm{D}$ to bring their serum $25(\mathrm{OH}) \mathrm{D}$ levels above $40 \mathrm{ng} / \mathrm{mL}$ (100 nmol/L), the level that has generally been found associated with optimal health. Vitamin D3 (cholecalciferol) would probably be more effective than vitamin D2 (ergocalciferol).

Funding: I received funding from the UV Foundation (McLean, VA), the Vitamin D Society (Canada), the European Sunlight Association (Brussels), and Bio-Tech-Pharmacal (Fayetteville, AR).

William B. Grant, Ph.D.

Sunlight, Nutrition, and Health Research Center (SUNARC)

P.O. Box 641603

San Francisco, CA 94164-1603, USA

Email:wbgrant@infionline.net

Tel: 1-415-409-1980

\section{References}

1 Kessler U, Ebneter M, Zachariou Z, Berger S. Postoperative sepsis in infants below 6 months of age. World J Pediatr 2009; 5:113-117.
2 Mookherjee N, Rehaume LM, Hancock RE. Cathelicidins and functional analogues as antisepsis molecules. Expert Opin Ther Targets 2007;11:993-1004.

3 Danai PA, Sinha S, Moss M, Haber MJ, Martin GS. Seasonal variation in the epidemiology of sepsis. Crit Care Med 2007; 35:410-415.

4 Grant WB. Solar ultraviolet-B irradiance and vitamin D may reduce the risk of septicemia. Dermatoendocrinol 2009;1: $37-42$.

5 Jeng L, Yamshchikov AV, Judd SE, Blumberg HM, Martin GS, Ziegler TR, et al. Alterations in vitamin D status and antimicrobial peptide levels in patients in the intensive care unit with sepsis. J Transl Med 2009;7:28.

doi:10.1007/s12519-010-0034-1

\section{Author reply}

$\mathrm{W}$ e read this letter with much interest and thank the editor for giving us the chance to make some comments. As the design of the reported study ${ }^{[1]}$ was observational and retrospective, conclusions on preventive strategies can only be drawn with caution. According to our results, lower postnatal age and major surgical interventions (e.g., laparotomy with incision of the intestines, or long duration of surgery) are important risk factors for postoperative sepsis syndrome in infants below six months of age. In particular, it was not an aim of our study to investigate the role of vitamin D in postoperative sepsis. We can thus only speculate whether vitamin D supplementation has a potential for prevention of postoperative sepsis. According to a Swiss recommendation in $1998,{ }^{[2]}$ which is in line with the current recommendation of the Lawson Wilkins Pediatric Endocrine Society in 2008, ${ }^{[3]}$ all patients included in our investigation had received 400 IU vitamin D daily since the fifth day of life. It is a current practice in our institution to supplement preterm infants with even larger doses, usually $600-800$ IU daily ${ }^{[3]}$ Nonetheless, we cannot exclude that some infants might have suffered from hypovitaminosis D in our patient cohort.

Since newborn vitamin D levels strongly rely on maternal vitamin D status, ${ }^{[4]}$ some infants operated on before day 5 and thus not yet supplemented, may have been vitamin D deficient. Furthermore, parental compliance to the recommended vitamin D substitution after discharge is unknown. In addition, hypovitaminosis D may complicate general 
undernutrition, in particular in patients in developing countries and the impact of vitamin D deficiency under these circumstances may be much more pronounced. Precise appraisal of vitamin D status in pregnant women is difficult, and not part of current obstetrical practice. ${ }^{[5]}$

We agree that more research is warranted to elucidate the etiology of postoperative sepsis, possible risk factors and thus also prevention strategies. Considering that vitamin $\mathrm{D}$ is a powerful inductor of antimicrobial peptide cathelicidin, which may play an important role in innate host defense, we also agree that vitamin $\mathrm{D}$ is a promising substance to promote sepsis prevention in hospitalized patients. ${ }^{[6]}$ However, there is an important lack of knowledge firstly on pediatric patients, secondly on the alterations of the vitamin $\mathrm{D}$ metabolism during critical illness, and thirdly on the role of vitamin $\mathrm{D}$ in perioperative complications. Furthermore, in neonates and infants the definition of normal ranges for vitamin D levels is still being debated. According to Zeghoud et $\mathrm{al}^{[7]}$ neonatal $25-\mathrm{OHD}$ concentrations $<30 \mathrm{nmol} / \mathrm{L}(12 \mathrm{ng} / \mathrm{ml})$ might signify an adequate cut-off for hypovitaminosis $\mathrm{D}$ in newborns since these values correlated with increasing parathyroid hormone. Specifically, the causal relationship between low vitamin D levels and infectious complications in children has not yet been investigated in vivo.

In conclusion, our study does not allow us to draw conclusions on current recommendations of vitamin D supplementation. However further research on the involvement of vitamin $\mathrm{D}$ in perioperative complications, especially in small infants, is needed.
Ulf Kessler, Zaccharious Zacchariou, Luregn J Schlapbach, Steffen Berger

Department of Pediatric Surgery (UK, ZZ, SB)

Department of Pediatrics (LS)

Inselspital, Bern University Hospital and University of Bern, 3010 Bern, Switzerland

Email:Ulf.Kessler@insel.ch

\section{References}

1 Kessler U, Ebneter M, Zachariou Z, Berger S. Postoperative sepsis in infants below 6 months of age. World J Pediatr 2009;5:113-117.

2 Baerlocher K, Baehler O, Belli D, Braegger C, Deleze G, Gaze $\mathrm{H}$, et al. Empfehlungen für die Säuglingsernährung 1998. Schweizerische Gesellschaft für Pädiatrie. Schweizer Aerztezeitung 1998;79:1143-1146.

3 Misra M, Pacaud D, Petryk A, Collett-Solberg PF, Kappy M. Vitamin D deficiency in children and its management: review of current knowledge and recommendations. Pediatrics 2008;122:398-417.

4 Salle BL, Delvin EE, Lapillonne A, Bishop NJ, Glorieux FH. Perinatal metabolism of vitamin D. Am J Clin Nutr 2000;71:1317S-1324S.

5 Pehlivan I, Hatun S, Aydogan M, Babaoglu K, Gokalp AS. Maternal vitamin D deficiency and vitamin D supplementation in healthy infants. Turk J Pediatr 2003;45:315-320.

6 Jeng L, Yamshchikov AV, Judd SE, Blumberg HM, Martin GS, Ziegler TR, et al. Alterations in vitamin D status and antimicrobial peptide levels in patients in the intensive care unit with sepsis. J Transl Med 2009;7:28.

7 Zeghoud F, Vervel C, Guillozo H, Walrant-Debray O, Boutignon $\mathrm{H}$, Garabedian M. Subclinical vitamin D deficiency in neonates: definition and response to vitamin D supplements. Am J Clin Nutr 1997;65:771-778.

doi:10.1007/s12519-010-0035-0 